\title{
Virtual Enterprise in Closed-Loop Supply Chain and Performance Evaluation Based on Exergoeconomics
}

\author{
Guojun Ji \\ School of Management, Xiamen University, Xiamen 361006, Fujian, P.R. China \\ jiking@xmu.edu.cn
}

\begin{abstract}
Based on analyzing the difficulties of closed-loop supply chain operation management, considering the new environment as the economic society developing continuously and discussing the feasibility of virtual enterprise, an operation management mode for the closed-loop supply chain based on virtual enterprise is presented in this paper. The organization framework, the operational process, the dynamic durative of virtual enterprise with traditional management mode is expounded in detail. Using the exergoeconomics theory, the closed-loop supply chain is regarded as a huge energy system with the new view, and the sustainability of the closed-loop supply chain system is discussed under the circumstance of exergoeconomics in this paper, and then the metric about "system negative environment effect" is introduced to measure closed-loop supply chain system performance from the point of energy. Finally a case study illustrates our conclusion.
\end{abstract}

Keywords: Closed-loop supply chain, Virtual enterprise, Exergoeconomics

\section{INTRODUCTION}

Rapidly globalizing markets, production and distribution systems operating within complex and fluid capital markets have triggered exceptional economic and competitive pressures in national economies. Consequent microeconomic reform, deregulation and the corporatization and privatization of national market places have been no less significant and have further impacted on nation-wide, as well as international, global logistics systems so that change is now pervasive, urgent and transforming. For buyers of freight services, whether manufacturers, rural and primary producers or retail giants, the pressing need to control costs in supply chains has spawned numerous strategies within a broader supply chain management framework that seeks sophisticated levels of operational as well as corporate integration-and ideally, fully integrated corporate and intercorporate business processes. For sellers of freight services-traditional "transport" providers now best described as third party logistics providers or fourth party service providers. They provide the outsourcing service of reverse logistics to the companies, intervene between buyer or shipper and customer-the focus on value delivery in competitive markets and are underlying urgent attempts to expand control over freight activities and to capture an increased share of value over the entire movement chain. It is resulting in rapidly restructuring corporate and value delivery systems. Therewith, 
over the last several years, changes in environmental laws and the new returns demands of market returns have raised the requirement for effective reverse logistics to a new level, reverse logistics issues are gaining justifiable popularity among society, governments and industry worldwide. They are mainly regulatory-driven in Europe, consumer-driven, market-driven and profit-driven in North America and in incipient stage in other parts of the world, including China, where both consumer awareness and globalization are likely to lead to greater economic, consumer and regulatory pressures in the coming future. Only very recently, some companies in consumer durables' and automobile sectors in China have introduced exchange offers to tap customers who already own such products. Presently, these returned products are either resold directly or after repair and refurbishment by firm franchisee/ local remanufacturers in the seconds' market. They are not remanufactured or upgraded by original equipment manufacturers (OEMs). In Chinese society is particularly price sensitive and to a little extent quality sensitive (quality for a given price) but not environment sensitive in its buying and promotion behavior in past years. Therefore, reverse logistics has not received the desired attention and is generally carried out by the unorganized sector for some recyclable materials such as paper and metal. As well, manufacturers must deal with returns from retailers, the channels of distribution, or end customers with warranty issues. To the cement supply chains, they are faced with environmentalist, so they must consider return activities, such as exhaust emission and waster disposal, dismoded cement recall etc. For example, in 2005 there was more the emitted cement tunnage's amount than two cement factories outputs, reported by Chinese News. In 2001 there were about 40 million desktops and mobile Personal Computers sold. About 9 million $(23 \%)$ of these were sold through retail stores. The retailer experienced a return rate of about $10 \%$ or 900,000 Units. Each of these units is estimated to cost the retailer $\$ 40-\$ 50$ to process and ship back to the manufacturer or to dispose of the units. The manufacturers estimate that each return costs them about $\$ 500$ each. This adds up to a whopping $\$ 486$ million. Each return is taking the manufacturers from 4 to 12 weeks to fully process. Returns are a small percentage of sales for the retailer or manufacturer, however, in high volume environments like consumer goods, this small percentage adds up to a large reverse logistics problem [1].

The term closed-loop supply chain (CLSC) has not appeared as such in the literature on supply chain and operations management until the beginning of this century. Several authors have spoken of 'reverse supply chains', a topic which was mainly discussed in practitioner circles [2]. However, a clear definition of CLSC only seems to have emerged thereafter. In their earlier work, CLSCs for refillable containers, photocopier remanufacturing and the re-use of consumer electronics are discussed in [3]. Probably the first contributors in designing a CLSC were Thierry et al. with their model of an 'integrated supply chain' [4]. This chain of companies has been defined as a supply chain, which comprises service, product recovery, and waste management activities. In this model, products return from the end-user to undergo a product recovery operation, such as re-use, repair, remanufacture or recycling. Thereafter, products are integrated back into the 'forward' supply chain. CLSC Management includes processes and operations that can not be found in conventional supply chain management. Krikke et al. explain that a CLSC consists of a forward and a reverse chain [5]. Guide and Van Wassenhove [6] further add that the additional 
activities the reverse supply chain includes comprise product acquisition, reverse logistics, test, sort, disposition, refurbish as well as distribution and marketing. While there are a variety of theoretical considerations for conventional supply chain management, there is still a lack of a theory for CLSC management, particularly with regard to the additional elements that the reverse supply chain incorporates. The rapid change of science and technology results in the diversity reduction which based on the production cost and the core technology. CLSC management has become an important strategy for enterprises and even countries to seizure the global plateau. With the industrial ecology issues are extensive popularity among the fields of society, government and industry etc. such as $3 \mathrm{R}$ (reducing, reusing and recycling) strategies, cost-saving ecological ideas and programmes, green teams and so on. On the other hand, the leading actors in today's markets have transformed from sellers to buyers, whether or not meet customers' individuation demands become an important factor to show enterprises' talents in the competitive environment. The concept of virtual enterprise was proposed by Kenneth Preiss, Steven L. Goldman, and Roger N. Nagal in 1991 in their report called "21st Century Manufacturing Enterprises Strategy: An Industry-Led View" [7]. The way of only depending on a single enterprise to respond rapidly to changing market opportunities and intensely global competition have been inapplicable. The key technique determined by utilizing agile manufacturing practices is based on virtual enterprise. CLSC operation management is restricted by the cost, the practice, and the human resource etc. Considering the environmental consciousness and the policy impact, the outsourcing for the segmental activities (such as reverse logistics) of CLSC is the better selection for the enterprises driven by economic profit. In order to make full use of the third provider services' advantage, virtual enterprise will be most appropriate.

The concept of exergy, a parameter in thermodynamics, was presented at first by $Z$. Rant in 1956. With several decades of development, the exergy analysis has become the basic theory and a useful tool in analyzing the energetic system and has obtained attention and application widely. Thermodynamics considered economics appears the exergoeconomics. Based on the theory of exergetic cost, it is applied in design analysis and optimization, operation optimization and diagnostics etc. Exergy has been proved to be suitable as a common quantifier of the sustainability of a system by Marc A. Rosen et al. and Ibrahim Dincer, etc [8]. Supply chain management by using exergoeconomics is nearly a new field. Based on the traditional exergoeconomics theory, Bai et al. [9] introduced environment effect factor as the measurement of supply chain system evaluation considered the sustenance of environment and resource. However, there are limitations in identification of the coefficient and no case study supported.

In this paper, an operation management mode for CLSC based on virtual enterprise is presented in this paper. The organization framework, the operational process, the dynamic durative of virtual enterprise, and the comparison with traditional management mode are expounded in detail. Based on the exergoeconomics theory, the sustainability of CLSC system is discussed, and then the metric about "system negative environment effect" is introduced to measure CLSC system performance in the point of energy, a case study illustrates our conclusion. 


\section{VIRTUAL ENTERPRISE AND CLSC OPERATION}

\subsection{The Framework of Organization}

The difficulties of CLSC management are enlarged by lots of partners and their flexibility. Hence a "leader enterprise or organization" is necessary to administer the virtual enterprise, namely the core enterprise. The sponsor manufacturer always plays the role of core enterprise; the reverse activities depend on the fourth service provider is also an appropriate option.

Comparing with the traditional organization structure, the virtual enterprise organized by two layers (core enterprises and non-core enterprises) is flat, availing interaction of partners. The flat structure is easy to respond the rapid changing market, as well as to eliminate the information distortion effectively. There are three main reverse logistic functions: collection, inspection/sort, and reprocessing. Collection refers to bringing the products from the customer to a point of recovery, including return, transportation, and storage. At this point the products are inspected, i.e. their quality is assessed and a decision is made on the options of disposal, according to that the products are sorted. The disposal of reprocessing includes the following options: direct reuse, repair, recycling, remanufacturing and harmless disposal. The type of recovery can be separated between product recovery, component recovery, material recovery and energy recovery. The abovementioned functions are necessary for CLSC. Based on virtual enterprise operation, subdividing the functions to several independent enterprises by integrating their core competencies is just the advantage we seek for, e.g., lowering cost, evading risk, etc. Therefore, the organization frame of CLSC operation management based on virtual enterprise can presented, as shown in figure 1.

\subsection{The Process of Operation Management}

Table 1 depicts the process of CLSC operation management based on virtual enterprise, which follows four phases:

Identifying opportunity: In order to utilizing the rapid response attribution of virtual enterprise with respect to the uncertainties of CLSC, enterprises in CLSC have to track the trends of market development timely. A mass of collected data using for forecasting should be from enterprises, customers, industries, markets, legislation and so on. The useful information will be evaluated relative to reliability, worthiness, feasibility.

Constructing organization: Based on abovementioned, virtual enterprise means the integration of the core competencies for participating in supply chain. Therefore identifying the core competency, evaluating the alternative enterprises and estimating the entire performance are crucial, that directly influence the operation efficiency of CLSC. The core competencies concerning CLSC reflect return channels, logistics capabilities, research \& development technology, manufacture arts and crafts, assets 
proprietary etc., determined by the relevant decision support system (DSS). Information system and the logistics network are necessary absolutely to support the virtual enterprise.

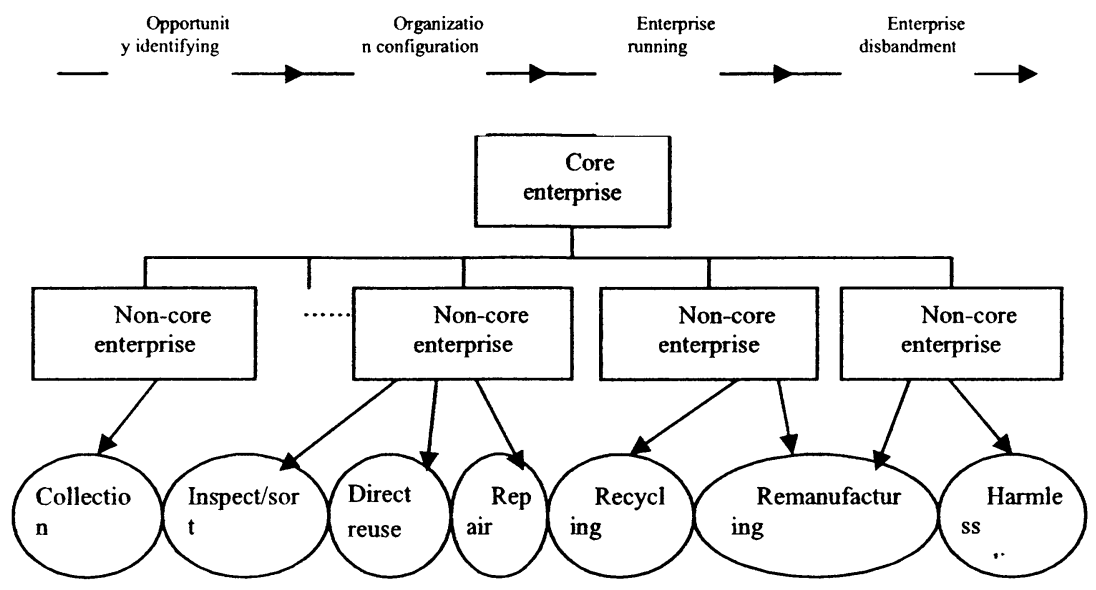

Figure 1. The Organization Framework of Virtual Enterprise for CLSC

Table 1. The Operation Management Mode of CLSC Based on Virtual Enterprise

\begin{tabular}{l}
\hline Opportunity identifying \\
$\checkmark$ information collection \\
$\checkmark$ data mining \\
$\checkmark$ analysis and estimate \\
\hline Organization configuration \\
\hline$\checkmark$ the core competency identifying \\
$\checkmark$ evaluating and selecting partners \\
$\checkmark$ the information system and CLSC network \\
$\checkmark$ estimating the holistic performance \\
\hline$\quad$ Enterprise running \\
$\checkmark$ coordination mechanism \\
$\checkmark$ dynamic contract \\
$\checkmark$ risk identification and control \\
$\checkmark$ monitor system and improvement \\
\hline Enterprise disbandment \\
$\checkmark$ the assets liquidation \\
$\checkmark$ knowledge management \\
\hline
\end{tabular}

Organization operation: The organization form of virtual enterprise is at the expense of coordination among partners. It implies that the excellent organization management is the precondition of virtual enterprise operation. The operation management is extended to the application of coordination mechanism, dynamic contract by stages, risk identification and control etc. As the dynamic developing, 
examine the operation status continuously, and improve the process according to the feedback.

Organization disbandment: The disbandment of virtual enterprise takes place after the disappearance of market opportunity. There is the assets liquidation among partner enterprises. The knowledge management runs through the whole operation management of virtual enterprise.

\section{MODEL INTRODUCED AND CASE STUDY}

Firstly, the exergy analysis is extended to take the environmental impacts of CLSC system into consideration. CLSC system influences the environment because of the waste discharged by it which includes two parts: one is from the emitted heat; the other is the physical exergy and chemical exergy of the waste itself. However, the various components in the wastes, with different chemical nature, bring different harm to the environment. A harm coefficient can be defined to denote this. Environment negative effect is defined as $E N E, E N E=\sum_{i} B_{i} E_{x, i}$, where $E_{x, i}$ denotes the physical and chemical exergy of the component $i$ in the system's wastes; and $B_{i}$ is the harm coefficient of component $i$ to the environment.

Secondly, the exergy analysis can be extended to assess the comprehensive effect of CLSC system considered resource and environmental impact. So, while dealing with the total effect of CLSC system, the exergy discharge loss should be considered twice, resource waste in the total exergy loss of the system, and impact on the environment in the $E N E$. However, the resource waste and the environment pollution can not be considered as equal, so the effect coefficient is introduced to use here. The system negative effect $(S N E)$ is defined as $S N E=C_{1} E_{x l, t o t}+C_{2} E N E$, where, $E_{x l, t o t}$ is the total exergy loss of the system; $C_{1}$ and $C_{2}$ are the effect coefficients. It is difficult to determine the effect coefficient of the system's negative effect, since resource waste cannot be compared with environmental pollution in a direct way. To solve this problem, the economic losses often are used to determine the effect coefficients. Let the exergy loss of the system represents as $E_{x L}=\Delta M+\Delta P+R$, where $\Delta M$ is the material loss of the system, $\Delta P$ is the product loss of the system, and $R$ denotes the residual of the system. Then the economic loss caused can be calculated by the equation that $E_{e L}=\sum E_{x L} P_{i n}$, where $P_{i n}$ denotes the average input exergy cost of the system.

SNE is an absolute variable, which can be used to evaluate different models of the systems with the same type or the different designed systems, but cannot be used to evaluate the different types systems. So a relative variable $S N E F$ is defined as $S N E F=\frac{S N E}{E_{x, i n}}$, where, $S N E F$ is factor of $S N E$, and $E_{x, i n}$ denotes the system's input exergy. 
We consider that two cement CLSC systems, A and B, are as follows. The flow charts of system A and B are shown in figure 2.

In succession, using by exergoeconomics and in view of the resource utilization and environmental impact, the calculation and analysis of the sustainability of the abovementioned cement CLSC systems performance is considered as follows.

(1) Calculate the input exergy, the output exergy, the whole system exergy and the physical and chemical exergy of all wastes in these two CLSC systems. Since the harm coefficients are hard to determined, we use the emissions limit for secondary standard in Cement Factory Atmosphere Emissions Standard constituted by China Environment Protection Department (GB 4915-1996) as the harm coefficients. So the environmental negative effect in supply chain system $A$ is
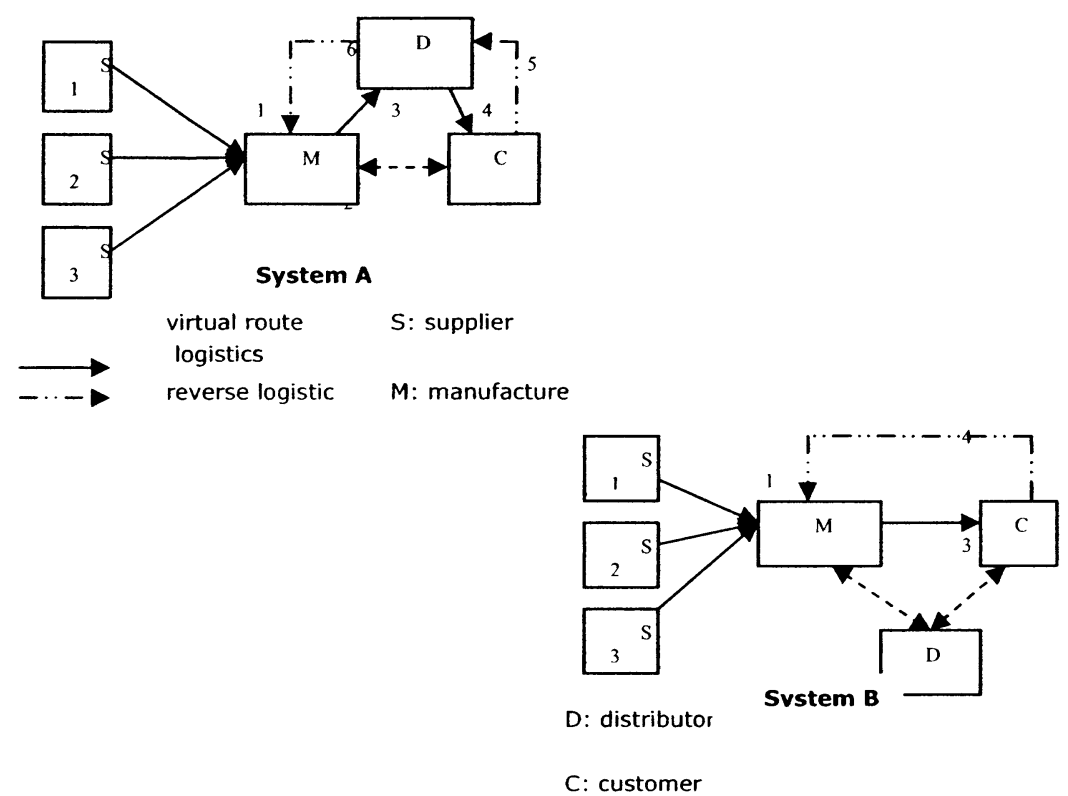

Figure 2. Flow Charts of Cement CLSC Systems A and B

$$
\begin{aligned}
& E N E=0.00006 \times 10^{6} \times 0.9+21.1318 \times 10^{6} \times 1.0 \\
& +0.0006 \times 10^{6} \times 2.4+0.2376 \times 10^{6} \times 0.03=2.12 \times 10^{7} \mathrm{kj} / T
\end{aligned}
$$

and that in system $\mathrm{B}$ is $E N E=4.57 \times 10^{6} \mathrm{kj} / \mathrm{T}$.

(2) Calculate the economic loss caused by resource waste. It can be deduced by the average input exergy cost of a system multiplying the total exergy loss of the system. So the economic losses of resource waste in system $\mathrm{A}$ is $1,590,800 \mathrm{Y} / \mathrm{a}$, and that in system $B$ is $1,538,000 ¥ / a$. 
(3) Calculate the economic loss of environmental impact which caused mainly by the powdery dust, $\mathrm{CO}_{2}, \mathrm{SO}_{2}$ and other oxides emitted from the cement CLSC system. It can be divided into two parts, one is the influence on the natural environment and the other is that on human health. It is hard to quantify the economic loss of the natural environment caused by the system. To some extent, the pollutant penalties are established by the Environment Protection Departments, the processing cost to handle the contamination in the factories, cost of dust catcher and cloth for enveloping the powdery dust on trucks can reflect the approximate costs, so we can use the sum of these to denote the economic loss of environment effect in cement system $A$ is $222,000 ¥ / \mathrm{a}$, and that in system B is $191,000 ¥ / \mathrm{a}$.

The economic loss caused by the influence on human health can be calculated by the sum of direct and indirect economic loss. Cement powdery dust is a kind of harmful substances. Once one inbreathe it at the definite amount can result in diseases, such as lung disease, and it deteriorates the working ambience. Direct economic loss concludes medical cost, income loss and cost on dust protection measures for workers. Indirect economic loss is comprised of economic loss based on work delay and food pollution. Therefore, the economic loss of human health caused by both cement CLSC systems is $24,710 ¥ / a$. And then we can calculate the total economic loss of the cement supply chain system $A$ is $249,410 ¥ / a$, and that of system $B$ is about $215,710 ¥ / a$.

(4) So, we can calculate that, for system $\mathrm{A}, S N E$ is 2.888 and $S N E F$ is 0.0174 ; for system $\mathrm{B}, S N E$ is 0.272 and $S N E F$ is 0.0016 .

The calculation process and results show that the system negative effect factor can finally evaluate the resource utilization and environmental influence in CLSC system which are the two key aspects of the sustainability and can be used as an objective to further optimize CLSC. The results show a less effect coefficient of environment negative effect. This is because that in the method effect coefficient is calculated by economic loss. In the present system of price and pollution penalty, the resource waste plays a primary role in system negative effect. But with the increasing recognition of the environmental protection, much more restrict criteria of contamination discharge will be issued. Besides, the need for CLSC forces companies to think more of the reverse logistics. If not be responsible for the whole product life cycle, company will be punished or even excluded from the market place. Therefore, the proportion of the influence to the environment will rise as well.

It can be seen from the results that the main contamination released by the cement supply chain system is cement powdery dust. So the system should be improved by reducing the outgoing of powdery dust, for example, utilizing the advanced dust catcher and regulations for envelopment of the trucks and route or time period for the loading trucks. The negative effect coefficient of cement CLSC system B is much less than that of system $A$, this means that system $B$ is much better than system $A$ in sustainability. It can be easy to see that cement flow in system $A$ is more complicated than system B, thus resource waste increases, environment aggravates. In fact, according to reported in Chinese News, there are released amounts more than two cement factories annually. Therefore, sustainability of CLSC system decreases and system performance gets worse. 
Virtual Enterprise in Closed-Loop Supply Chain and Performance Evaluation Based on

\section{ACKNOWLEDGEMENTS}

This work is supported by new century outstanding talent plan in Fujian.

\section{REFERENCES}

1. G.J. Ji, Market-motivated value systems, reverse logistics and the evaluation model for the third party reverse logistics providers, International Logistics and Trade. Volume 4, Number 1, pp.53-92, (2006).

2. Morrell and A. L., The forgotten child to the supply chain, Modern Materials Handling Volume 56, Number 6, pp.33-36, (2001).

3. V.M. Smith and G.A. Keoleian, The value of remanufactured engines, Journal of Industrial Ecology. Volume 8, Number 1-2, pp.193-221, (2004).

4. M. Thierry, M. Solomon, N.J. Van, and W.L. Van, Strategic issues in product recovery management, California Management Review. Volume 37, Number 2, pp.114-137, (1995).

5. H.R. Krikke, J.B. Ruwaard, and L.N.V. Wanssenhove, Concurrent product and closedloop supply chain design with an application to refrigerators, International Journal of Production Research. Volume 41, Number 16, pp.3689-3719, (2003).

6. V.D.R. Guide and L.N.V. Wassenhove, Business Aspects of Closed-Loop Supply Chains. Exploring The Issues (Carnegie Mellon University Press: Pittsburgh, PA, 2003)

7. P. Kenneth, L.G. Steven, and N.N. Roger, 21st Century Manufacturing Enterprises Strategy: An Industry-Led View (Leihigh University Press: New York, NY, 1991)

8. Y.F. Wang and X. Feng, Exergy analysis involving resource utilization and environmental influence, Science in China (Series B). Number 1, pp.86-95, (2001).

9. S.Z. Bai, X.J. Zheng, and S.B, Wang, Application of exergoeconomics in supply chain management, Logistics Technology. Volume 10, Number 1, pp.1-2, (2005). 